NASA Technical Memorandum 89814

AIAA-87-2071

\title{
Comparison of Two Procedures for Predicting Rocket Engine Nozzle Performance
}

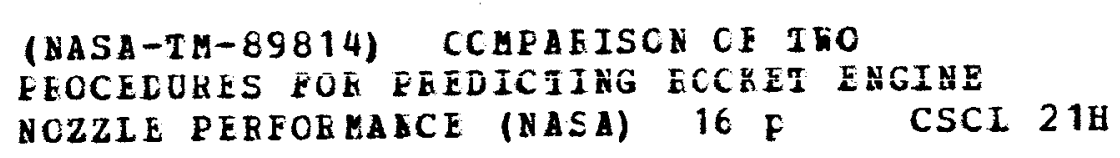

Kenneth J. Davidian

Lewis Research Center

Cleveland, Ohio

Prepared for the 23rd Joint Propulsion Conference cosponsored by the AIAA, SAE, ASME, and ASEE San Diego, California, June 29-July 2, 1987 
COMPARISON OF TWO PROCEDURES FOR PREDICTING

\title{
ROCKET ENGINE NOZZLE PERFORMANCE
}

Kenneth J. Davidian

\author{
National Aeronautics and Space Administration \\ Lewis Research Center \\ Cleveland, Ohio 44135
}

\section{Abstract}

Two nozzle performance prediction procedures which are based on the standardized JANNAF methodology are presented and compared for four rocket engine nozzles. The first procedure required operator intercedance to transfer data between the individual performance programs. The second procedure is more automated in that all necessary programs are collected into a single computer code, thereby eliminating the need for data reformatting. Results from both procedures show similar trends but quantitative differences. Agreement was best in the predictions of specific impulse and local skin friction coefficient. other compared quantities inciude characteristic velocity, thrust coefficient, thrust decrement, boundary layer displacement thickness, momentum thickness, and heat loss rate to the wall. Effects of wall temperature profile used as an input to the programs was investigated by running three wall temperature profiles. It was found that this change greatly affected the boundary layer displacement thickness and heat loss to the wal1. The other quantities, however, were not drastically affected by the wall temperature profile change.

\section{Introduction}

Accurate predictions of boundary layer growth are necessary for accurate predictions in rocket engine performance. Equilibrium and chemical kinetics programs already exist which predict performance losses with sufficient accuracy. However, the computer modeling of boundary layer growth and its effect on rocket engine performance is less standardized. This is due to differences in the physical modeling and numerical procedures used. Boundary layer losses start to detract greatly from the overall performance in rocket engine nozzle designs with large exit-area to throat-area ratios. These high area ratio nozzles (>400) are of interest for orbital transfer vehicles to obtain maximum performance as indicated by high specific impulse.

The purpose of this paper is to compare the results from two procedures for evaluating the performance of nozzle contours. Both procedures are based on the standardized JANNAF methodology 1 for predicting rocket engine nozzle performance. The first, the disjoint procedure, requires transmission of data between three separate performance prediction programs. The boundary layer prediction program in this procedure is BLIMP. 2 BLIMP is an independent, stand-alone program and can only be utilized after prior runs of other performance programs. In this case, two programs were run as an input to BLIMP. The second, the integrated procedure, utilizes one performance program which has many subroutines to perform the prediction. BLM ${ }^{3}$ was the boundary
1 ayer prediction program used in this procedure. Unlike BLIMP, BLM is accompanied by a set of subprograms which will calculate all the necessary preliminary information required for the boundary layer analysis. This total set of subprograms (including BLM) is referred to as the 1985 version of the Two-Dimensional Kinetics program (TDK.85).4

Performance comparisons were made for nozzles having area ratios $60: 1,200: 1,400: 1$, and 1000:1. Each nozzle had a throat diameter of 1 in. and was specified to run at a chamber pressure of 1000 psia using hydrogen and oxygen as the propellants. Variations of the wall temperature profile were made to investigate its effect on the engine performance.

\section{Description of Procedures}

The first procedure for evaluating the rocket engine nozzle performance is referred to as the disjoint procedure. The succession of programs used in this procedure is the oneDimensional Equilibrium (DDE) program, ${ }^{5}$ the One-0imensional Kinetics (ODK) program, 6 and the Boundary Layer Integral Matrix Procedure program (BLIMP).2 ODE is a thermochemical properties program which provided throat chemical composition input data for the ODK program. ODK, a kinetics program which computes finite rate reaction performance, was run from the nozzle throat to the exit. The results provide BLIMP with pressure profile and chemistry information as input. The exclusion of a two-dimensional kinetics analysis results from the fact that the 1973 version of the Two-Dimensional Kinetics program (TDK.73) was to be used, but it gave unstable results. Therefore, an average value for the equivalent two-dimensional divergence efficiency of 0.996 was assumed in lieu of running TDK.73. This divergence efficiency js equivalent to a $7.25^{\circ}$ divergence half-angle. 7 The flow diagram for this procedure is shown in Fig. 1. Table 1 shows the required inputs for each program used in the disjoint procedure and from which program (if any) they are generated.

The second procedure used is called the integrated procedure. In this study, the integrated procedure refers to a single program, the 1985 version of the TDK program (TDK.85). TDK. 85 combines TOK. 73 as a subprogram along with the boundary layer module (BLM), ODE, ODK, and many other subprograms into one large program. The inputs required for the integrated procedure are shown in Table 2.

\section{Description of Programs}

The individual programs described below are performance prediction codes. 
One-Dimensional Equilibrium Program (ODE)

This program calculates the equilibrium conditions for a reactive mixture in an idealized closed combustion system. Reaction rates are considered to be infinitely fast so that all reactions reach local equilibrium conditions. A rocket performance option is run which predicts the theoretical maximum performance of isentropic convergent-subsonic and divergent-supersonic flow in a nozzle with shifting equilibrium chemical composition during expansion. The results from ODE were used as throat condition inputs to the ODK program in the disjoint procedure.

One-Dimensional Kinetics Program (ODK) ${ }^{6}$

This program calculates the deviation from equilibrium performance in the nozzle due to finite reaction rates not allowing chemical equilibrium to be reached. Unlike ODE, ODK bases the fraction of mixture which will react on the reaction rates of the mixture. ODK considers complex, homogeneous, ideal gas reactions in combustion and nozzle expansion situations. Eighteen chemical reactions and four three-body recombinationdissociation reactions were used by 00K for the fuel/oxygen combination of hydrogen and oxygen (Table 3 ). The output from this program provides an axial pressure profile along a streamline boundary (i.e. the nozzle wall) as an input to the BLIMP program in the disjoint procedure. ODK also outputs performance results including specific impulse, thrust coefficient $\left(C_{F}\right)$, and characteristic velocity $\left(c^{*}\right)$.

Boundary Layer Integral Matrix Procedure Program $(\text { BL IMP) })^{2}$

This program calculates the boundary layer growth in a rocket nozzle. For axisymmetric flow, the program can calculate either shifting equilibrium or frozen compositions for any fuel/ oxidizer combination. The program uses an integral matrix solution algorithm which is equivalent to a higher order finite difference approach. This program will output various boundary layer properties as well as the coordinates of the potential flowfield if the input described the real wall, or the coordinates of the real wall if the potential flow contour was input.

Two-Dimensional Kinetics Program 1983 Version $\overline{(T D K .83)}^{3}$

This program is really a combination of programs. It incorporates the ODE and ODK programs along with a transsonic module (TRANS), a method of characteristics routine (MOC), a two-

dimensional kinetics effects module, and a boundary layer predictor (BLM). TDK.83 integrates all the pieces which were used in the disjoint procedure and passes the needed information between the programs automatically. The results of each run are printed out in a summary table at the end of a run. The program provides the user with the capability of using specific combinations of subroutines for each section of the engine. All the computations involved with analyzing a rocket engine nozzle are achieved with one computer run. This includes evaluation of the kinetic deviations from equilibrium performance, calculation of the sonic line in the throat region, setting up the mesh of characteristic lines, calculating the kinetics variances in the nozzle downstream of the throat, and predicting the boundary layer growth and losses. Also, the program can displace a potential wall contour by the displacement thickness calculated by BLM and recompute the kinetic variances in the nozzle to attain a better estimate of the boundary layer thickness.

\section{Description of Input Cases}

Four nozzles, with area ratios of $60: 1$, $200: 1,400: 1$, and $1000: 1$, were chosen for this evaluation study. All four had 0.5 in. throat radi $i$ and lengths corresponding to a 100 percent $15^{\circ}$ cone with the same throat radius and area ratio. 7 They all operated at 1000 psia chamber pressure and used normal boiling point (NBP) liquid hydrogen and NBP I iquid oxygen as their fuel and oxidizer. The propellants were injected with a mixture ratio $(0 / F)$ of six.

For the given area ratios, the nozzle exit radi $i$ were determined. These exit plane lengths and radi $i$ values are tabulated in Table 4 . Since the purpose of this study was comparative in nature, the actual contour of the nozzles was not important so long as they were the same for both procedures. The contour for each nozzle between the throat and exit plane was calculated using the RAO method, a method of characteristics routine coupled with an optimization scheme based on the calculus of variations. ${ }^{8}$ These contours (Appendix A) defined the potential flow boundaries for each nozzle.

The remaining operating conditions of the engine were used as inputs for ODK, BLIMP, and TDK. The energy level associated with the oxygen is $-2948 \mathrm{cal} / \mathrm{mole}$ and $-1977 \mathrm{cal} / \mathrm{mole}$ for the hydrogen. The geometry variables of the combustion chamber, throat, and nozzle are shown in Fig. 2 and the corresponding values are specified in Table 5 .

For both evaluation procedures, the potential wall contour was defined by specifying axial location values and radii at equal intervals along the nozzle centerline. In the integrated procedure, the number of contour points was greatly reduced at the higher area ratios $(>200: 1)$ to insure that the contour interpolating routine would not compute an erratic wall slope between input wall points. The number of points given for each area ratio for both procedures, the number of points on the sonic line at the throat (required to set-up the method of characteristics mesh), and the number of segments used in the boundary layer prediction (for the integrated procedure) is shown in Table 6 .

Each nozzle had the same baseline wall temperature profile. The wall temperature profile of the 1000:1 nozzle is shown in Fig. 3. The smaller area ratio nozzles used this same profile truncated at the axial position of the nozzle exit. The profile for all four nozzles assumed a cooled throat section, and a radiation cooled nozzle. Near the throat, the profile used is very similar to that calculated for the Space Shuttle Main Engine (SSME).2 It is much cooler in the throat region than the calculated temperature for the RL $10^{4}$ due to the difference in materials of construction. Figure 4 shows the wall temperature profiles of the 200:1 nozzle, 
the RL10, and the SSME superimposed on the same plot for comparison purposes.

\section{Discussion of Results}

The results of the computer runs showed similar trends for all the area ratios considered. The general discussion of results will cover all the nozzles investigated, however, only figures for the 1000:1 case will be shown since they are characteristic of all the results. The 1000:1 area ratio is also of particular interest for an orbital transfer vehicle. The quantities which are compared include the boundary layer displacement thickness, momentum thickness, local skin friction coefficient, thrust loss, heat loss to the wall, the characteristic velocity $\left(c^{\star}\right)$, thrust coefficient $\left(C_{F}\right)$, and specific impulse $\left(I_{S P}\right)$.

Boundary Layer Displacement and Momentum Thickness

Figure 5 is a comparison between the boundary layer displacement thickness as calculated by the disjoint procedure and the integrated procedure for the 1000:1 nozzle. The boundary layer dispiacement thickness predictions for the two procedures agree near the throat but then diverge monotonically toward the exit plane. Agreement between the two code's exit plane predictions is very good for the 60:1 area ratio case (only a 1.4 percent difference). However, the 200:1, $400: 1$, and 1000:1 cases show a 10.5, 39.6, and 35.8 percent difference between the exit plane values for the two procedures, respectively. The disjoint procedure predicts a greater displacement thickness value and rate of growth than does the integrated procedure. These differences between the two procedures in boundary layer displacement thickness are good examples of the reason for this study.

Figure 6 shows a comparison of the momentum thickness profiles in the axial direction as predicted by the disjoint procedure and the integrated procedure for the 1000:1 area ratio nozzle. The integrated procedure predicts a nearly linear increase in momentum thickness from the throat to the exit, while the disjoint procedure shows a gently concave profile which is always greater than the integrated procedure profile. This results in a slightly higher prediction by the disjoint procedure at the exit plane for every case. Differences between the two procedures' momentum thickness predictions are $11.6,11.3$, 18.4 , and 16.2 percent for the $60: 1,200: 1$, $400: 1$, and 1000:1 area ratio cases respectively.

A possible reason for the discrepancies between the two procedures is that the wall pressure profile resulting from the disjoint procedure was different than that used in the integrated procedure. In the disjoint procedure, the wall pressure profile was output from the ODK program and used as an input to the BLIMP program. In the integrated procedure, the wall pressures were calculated internally by the TDK subprogram. TDK will generally predict larger values of wall pressure than will ODK. The differences between these values for similar axial stations were as large as a factor of two. This large discrepancy $c$ an change the fluid properties at the edge of the boundary layer drastically. This, in turn, affects the boundary layer profiles as seen in the displacement or momentum thickness plots.
More subtle differences are found in the eddy-viscosity models used by the two boundary layer programs. These also directly affect the prediction of the boundary layer profiles. BLIMP uses the original Cebeci-Smith eddy-viscosity model whereas BLM uses a revised version of the same model. For example, BLM uses kinematic viscosity, intermittancy, and transitional terms in the near-wall region expression of the dimensionless eddy-viscosity whereas BLIMP does not.

\section{Local Skin Friction Coefficient}

Figure 7 shows the local skin friction coefficient for the 1000:1 nozzle. The local skin friction coefficient is defined as the ratio of shear stress at the wall to the local dynamic pressure. The closest agreement at the exit plane (a difference of 1.5 percent) occurs in the 1000:1 area ratio case and the largest difference (10.2 percent) occurs at the $400: 1$ area ratio.

\section{Thrust Decrement Due to Boundary Layer Growth}

The thrust decrement is the loss of thrust due to skin friction effects on the boundary layer displacement thickness and the wall pressure profile in the nozzle. Figure 8 shows the prediction comparisons of thrust decrement for the 1000:1 case. In all four area ratio cases the prediction at the throat by the disjoint procedure is greater than that of the integrated procedure. The integrated procedure diverges from the disjoint procedure solution downstream of the throat and predicts a greater value at the exit plane, as is shown in the figure. The thrust decrement predictions vary by $12.5,20.3,22.3$, and 32.2 percent for the $60: 1,200: 1,400: 1$ and 1000:1 nozzles, respectively.

Since the thrust decrement can be directly related to the size of the boundary layer, the reasons for the discrepancies between the two procedures are similar to those described in the displacement thickness section.

\section{Heat Loss to the Wall}

The heat loss to the wall profiles are derived from the integration of the amount of heat being directed at the nozzle wall per unit area per unit time. By integrating this quantity locally over the entire nozzle length, the result is a cumulative heating rate, with units of $B T U / \mathrm{sec}$. The value of heat loss to the wall is primarily dependent on the wall temperature profile and the heat transfer coefficient. Integration is performed by the computer programs. The comparison of the profiles of the total heat loss rate to the wall are characterized by the 1000:1 area ratio case, as shown in Fig. 9. The values predicted by the disjoint procedure are plotted starting from the throat whereas the integrated procedure's values begin approximately 20 percent of the nozzle length downstream of the throat. This is because the integrated procedure divides the nozzle into segments and gives an integrated heat flux value at the end of each segment. The values predicted by both procedures at this point show good agreement in the throat region. However, as the analysis travels down the nozzle toward the exit plane, the predicted values diverge rapidly. The difference between predicted values at the exit plane are 14.9, 20.0, 22.7, 
and 26.8 percent for the $60: 1,200: 1,400: 1$, and 1000:1 nozzles respectively. In all cases, the integrated procedure predicts a greater value of heat loss to the wall for the same wall temperature profile. The difference is probably due to the difference in wall pressure profiles used in the two procedures as well as a difference in the surface coefficients of heat transfer.

\section{Characteristic Velocity, $c^{*}$}

Analytically, the characteristic velocity, $c^{*}$, is a quantity which reflects the effective energy level of the propellants and subsonic expansion. Values for the characteristic velocity as predicted by both procedures are tabulated in Table 8. The characteristic velocity values predicted by the ODE portion of both procedures are constant for all area ratios. There is an almost negligible ( 0.2 percent) difference between the values calculated by the two procedures, with the disjoint procedure predicting a lower value than the integrated procedure. Differences between the thermodynamic datahases used in the disjoint and the integrated procedures' ODE versions can account for the difference in these predicted values.

At the boundary layer level of computations (accounting for the area change at the throat), the difference between the computed $c^{*}$ values are within 0.6 percent of each other. Again, the integrated procedure predicted a greater value than did the disjoint procedure.

The thermodynamic databases used in the integrated and disjoint procedures were different. This is most likely the cause of the differences between the two procedures.

\section{Thrust Coefficient, $C_{F}$}

Tabulated values of the thrust coefficient can be found in Table 8. The thrust coefficient as calculated by $O D E$ in both procedures show very good agreement. The variation in equilibrium values between procedures is less than 0.1 percent for all area ratios. This variation is caused by the thermodynamic database difference mentioned in the previous section.

In all cases, the integrated procedure consistently predicts a slightly higher $C_{F}$ value. The thrust coefficient for the two different procedures differs by $4.7,3.8,3.2$, and 2.4 percent for the $60: 1,200: 1,400: 1$, and $1000: 1$ area ratio cases, respectively.

This result taken with respect to the heat loss rate results point to an overall consistency between the two procedures. The disjoint procedure predicts a lower heat loss rate as well as a lower thrust coefficient.

Vacuum Specific Impulse, Isp

The vacuum specific impulse is a measure of the efficiency of a rocket engine. The thrust decrement is the loss of thrust due to boundary layer growth in the rocket nozzle. These two quantities are discussed together because the thrust decrement is converted to an impulse decrement and subtracted from the ideal value of $I_{S p}$ predicted prior to the boundary layer analysis.
The absolute specific imoulse values calculated by both procedures are all very close, as shown in Fig. 10. The predictions differ by 0.10 , $0.51,0.64$, and 1.30 percent for the $60: 1,200: 1$, $400: 1$, and the 1000:1 case, respectively. In all cases, the disjoint procedure predicts an I $s p$ value higher than those of the integrated procedure. The specific impulse calculated by the ODE portion of both procedures is within 0.25 percent due to thermodynamic database differences mentioned previously. The integrated procedure consistently predicts the larger value.

The discrepancies in the values of thrust decrement predictions translate directly to discrepancies in specific impulse loss discrepancies. The disjoint procedure predicts an I sp loss of $11.0,12.4,13.0$, and $13.6 \mathrm{sec}$ from the $60: 1$ nozzle to the 1000:1 nozzle. This contrasts sharply with the $12.7,15.6,16.8$, and $20.2 \mathrm{sec}$ losses which the integrated procedure predicts for the $60: 1$ to $1000: 1$ nozzles.

The disagreement in specific impulse at the 1000: 1 area ratio result (Table 8 ) is surprisingly low, especially in light of the large thrust decrement discrepancy between the two procedures. The two orocedures were in good agreement on specific impulse predictions.

Notes on Effects of Wall Temperature Profile on Results

In an attempt to investigate the effect of wall temperature profile on the predictions, the 200: 1 area ratio case was rerun using the integrated procedure with two different wall temperature profiles. The two new wall temperature profiles were the baseline wall temperature profile displaced by \pm 500 degrees Rankine (referred to as $+500^{\circ} \mathrm{R}$ and $-500^{\circ} \mathrm{R}$ wall temperature profiles, respectively). All three profiles are plotted in $\mathrm{Fig} .11$.

The effect of wall temperature profile on the momentum thickness, thrust decrement, and local skin friction coefficient is small (i.e., less than 5 percent) for both profiles. Likewise, the values of vacuum specific impulse, $c^{*}$, and $C_{F}$ were all within 0.17 percent of the baseline calculations for both wall temperature profiles. The displacement thickness predicted by the integrated procedure using the $+500^{\circ} \mathrm{R}$ wall temperature profile is 14.8 percent greater and the $-500{ }^{\circ}$ wall temperature profile is 15.0 percent less than the original predictions (Fig. 12). The effect of the $+500^{\circ}$ temperature profile on heat loss rate resulted in a 7.8 percent exit plane value decrease from the baseline value and the -500 Rall temperature profile resulted in a 6.1 percent exit plane value increase (Fiq. 13).

Based on this comparison, the prediction by the integrated procedure of the momentum thickness, local skin friction coefficient, and thrust decrement is seen to be relatively insensitive to wall temperature profile, whereas the displacement thickness and heat loss predictions are very sensitive. This indicates that if the analysis being done is for nozzle design, the wall temperature is a very critical input. A nozzle with too great or too small of a potential wall displacement will result in different exit pressures, Mach numbers, and wall angles than those desired. However, if 
the analysis is to determine specific impulse or skin friction of an already fabricated nozzle, an approximate temperature profile can be used to yield satisfactory results.

\section{Concluding Remarks}

An analytical study was conducted which compared the outputs from two different procedures, both of which followed the standard JANNAF methodology of predicting liquid rocket engine performance. The predicted values by both procedures of characteristic velocity and thrust coefficient are within 0.6 and 3.0 percent of each other, respectively. Predicted vacuum specific impulse values are within 1.3 percent of each other. Comparing these parameters alone, the two procedures displayed good agreement between themselves.

However, the procedures' predictions of displacement thickness and skin friction coefficient were within a maximum difference of approximately 10 percent, momentum thicknesses were within 20 percent, heat loss rates were within 30 percent, and thrust loss due to bouridary iayer growth was within 40 percent. This was due to the differences between the two procedures' input wall pressure profiles and physical models (e.g. Cebeci-Smith eddy-viscosity model). Upon inspection of these parameters, agreement between the two procedures can be seen to be poor. Experimental test results are required to pinpoint which (if either) of the two procedures better models the real situation.

Therefore, if approximate values of the gross performance parameters are the object of the analysis, either procedure will produce a value within current measurement accuracy limits of the other. It can also be seen, then, that if accurate axial profiles of the boundary layer quantities are desired, the procedure used for even the choice of boundary layer modules) will greatly affect the result. The disjoint procedure predicts greater values of displacement thickness, and momentum thickness, and lower values of skin friction coefficient, thrust decrement, and heat loss rate profiles, as compared to the integrated procedure.

Effect of wall temperature profile on reported parameters was investigated by displacing the baseline wall temperature profile by $\pm 500^{\circ} R$. Less than \pm 0.2 percent change was experienced by values of characteristic velocity, thrust coefficient, vacuum specific impulse, and skin friction coefficient. Parameters which showed less than \pm 5 percent change included momentum thickness and thrust decrement. Greatly affected by the change in wall temperature profile were boundary layer displacement thickness (changed by 15 percent) and heat loss rate (which displayed a \pm 7 percent change).

Other areas of concern deal with the operation of the computer programs themselves. Com- pletion of an analysis of one rocket nozzle for the disjoint procedure required considerably more clock time than did one run for the integrated procedure. This was due to the manual transmission and reconditioning of data from the output of one computer program to the input of the next computer program. Moving the data between programs in the disjoint procedure was done as carefully as possible and it was assumed that no error was introduced because of incorrect data entry. However, this resulted in increasing the complexity of the analysis and prolonged the amount of time required to do an entire performance prediction analysis. Automated interfacing between programs was a major step forward with the introduction of TDK.85 (i.e., the integrated procedure). The integrated process eliminated this possible source of error and also reduced the total time required for a thorough analysis.

\section{References}

1. "JANNAF Rocket Engine Performance Prediction and Evaluation Manua 1," CPIA-PUBL-245, Chemical Propu1sion Information Agency, Laurel, i⿵门̂, Apr. 1975.

2. Evans, R.M., "Boundary Layer Integral Matrix Procedure for JANNAF, BLIMP-J User's Manual," Aerotherm-UM-75-64, Aerotherm Acurex Corp., Mountain View, CA, July 1975. (NASA CR-144046)

3. Nickerson, G.R., Coats, D.E., and Dang, L.D., "Two-Dimensional Kinetic Reference Computer Program, (TDK)," NASA CR-178628, 1985.

4. Nickerson, G.R. and Dang, L.D., TwoDimensional Kinetics Computer Program for Orbit Transfer Vehicles," 22nd JANNAF Combustion Meeting, Vol. 1, D.S. Eggleston, ed., CPIA-PUBL-432-VOL-1, Chemical Propulsion Information Agency, Laure 1, MD, 1985.

5. Gordon, S. and McBride, B.J., Computer Program for Calculation of Complex Chemical Equilibrium Compositions, Rocket Performance, Incident and Reflected Shocks, and ChapmanJouguet Detonations," NASA SP-273, 1976.

6. Bittker, A. and Scullin, V.J., "General Chemical Kinetics Computer Program for Static and Flow Reactions, with Application to Combustion and Shock-Tube Kinetics," NASA TN D-6586, 1972.

7. Huze1, D.K. and Huang, D.H., "Design of Liquid Propellant Rocket Engines," 2nd ed., NASA SP-125, 1971.

8. Rao, G.V.R., "Exhaust Nozzle Contour for Optimum Thrust," Jet Propulsion, Vol. 28, No. 6 , June 1958, pp. 377-382. 
APPENDIX A

INVISCID CONTOUQS

\begin{tabular}{|c|c|c|c|c|c|c|c|}
\hline \multicolumn{2}{|c|}{$E=60: 1$} & \multicolumn{2}{|c|}{$E=200: 1$} & \multicolumn{2}{|c|}{$E=400: 1$} & \multicolumn{2}{|c|}{$E=1000: 1$} \\
\hline $\begin{array}{l}\text { R, } \\
\text { in. }\end{array}$ & $\begin{array}{l}\text { z, } \\
\text { in. }\end{array}$ & $\begin{array}{l}\text { R, } \\
\text { in. }\end{array}$ & $\begin{array}{l}\text { z, } \\
\text { in. }\end{array}$ & $\begin{array}{l}\text { R, } \\
\text { in. }\end{array}$ & $\begin{array}{l}\text { z, } \\
\text { in. }\end{array}$ & $\begin{array}{l}\text { R, } \\
\text { in. }\end{array}$ & $\begin{array}{l}\text { z, } \\
\text { in. }\end{array}$ \\
\hline $\begin{array}{l}0.50000 \\
.52980 \\
.56325 \\
.59797 \\
.63416 \\
.67215 \\
.71218 \\
.75426 \\
.79958 \\
.84938 \\
.90556 \\
.96802 \\
1.0390 \\
1.1210 \\
1.2121 \\
1.3150 \\
1.4255 \\
1.5447 \\
1.6673 \\
1.7947 \\
2.0089 \\
2.1994 \\
2.4603 \\
2.6743 \\
2.9330 \\
3.1450 \\
3.3071 \\
3.5316 \\
3.7040 \\
3.8729\end{array}$ & $\begin{array}{c}0.00000 \\
.10597 \\
.16766 \\
.22951 \\
.29209 \\
.35607 \\
.42222 \\
.49182 \\
.56659 \\
.64881 \\
.74142 \\
.84720 \\
.97000 \\
1.1142 \\
1.2820 \\
1.4776 \\
1.6998 \\
1.9494 \\
2.2218 \\
2.5208 \\
3.0658 \\
3.6005 \\
4.4208 \\
5.1883 \\
6.2492 \\
7.2652 \\
8.1523 \\
9.6024 \\
10.965 \\
12.641\end{array}$ & $\begin{array}{l}0.50000 \\
.55153 \\
.59457 \\
.63923 \\
.68588 \\
.73490 \\
.78640 \\
.84161 \\
.90207 \\
.96987 \\
1.0459 \\
1.1331 \\
1.2343 \\
1.3497 \\
1.4821 \\
1.6303 \\
1.7915 \\
1.9648 \\
2.1468 \\
2.3386 \\
2.6997 \\
3.0833 \\
3.4157 \\
3.8634 \\
4.3107 \\
4.6689 \\
5.0843 \\
5.4424 \\
5.9134 \\
6.4260 \\
6.8083 \\
7.0711\end{array}$ & $\begin{array}{c}0.00000 \\
.13874 \\
.20374 \\
.26926 \\
.33600 \\
.40467 \\
.47662 \\
.55344 \\
.63747 \\
.73163 \\
.83929 \\
.96480 \\
1.1129 \\
1.2880 \\
1.4949 \\
1.7361 \\
2.0114 \\
2.3201 \\
2.6604 \\
3.0379 \\
3.8075 \\
4.7110 \\
5.5728 \\
6.8626 \\
8.3208 \\
9.6290 \\
11.333 \\
12.994 \\
15.518 \\
18.868 \\
21.976 \\
24.576\end{array}$ & $\begin{array}{l}0.50000 \\
.55388 \\
.60268 \\
.65319 \\
.70587 \\
.76129 \\
.81966 \\
.88227 \\
.95098 \\
1.0283 \\
1.1155 \\
1.2160 \\
1.3331 \\
1.4679 \\
1.6232 \\
1.7988 \\
1.9917 \\
2.1993 \\
2.4194 \\
2.6539 \\
3.1041 \\
3.5887 \\
4.0157 \\
4.6000 \\
5.1980 \\
5.6854 \\
6.2638 \\
6.7733 \\
7.4628 \\
8.2451 \\
8.8592 \\
9.3302\end{array}$ & $\begin{array}{c}0.00000 \\
.13949 \\
.20635 \\
.27376 \\
.34248 \\
.41340 \\
.48771 \\
.56736 \\
.65477 \\
.75311 \\
.86613 \\
.99859 \\
1.1558 \\
1.3429 \\
1.5652 \\
1.8263 \\
2.1265 \\
2.4644 \\
2.8396 \\
3.2588 \\
4.1248 \\
5.1512 \\
6.1401 \\
7.6336 \\
9.3425 \\
10.888 \\
12.919 \\
14.915 \\
17.977 \\
22.086 \\
25.944 \\
29.418\end{array}$ & $\begin{array}{c}0.50000 \\
.55639 \\
.61461 \\
.67446 \\
.73637 \\
.80116 \\
.87004 \\
.94477 \\
1.0277 \\
1.1196 \\
1.2243 \\
1.3461 \\
1.4883 \\
1.6536 \\
1.8453 \\
2.0638 \\
2.3063 \\
2.5693 \\
2.8505 \\
3.1532 \\
3.7441 \\
4.3913 \\
4.9708 \\
5.7804 \\
6.6255 \\
7.3290 \\
8.1803 \\
8.9475 \\
10.013 \\
11.267 \\
12.295 \\
13.116 \\
14.326 \\
15.811\end{array}$ & $\begin{array}{c}0.00000 \\
.14022 \\
.20968 \\
.27976 \\
.35120 \\
.42507 \\
.50288 \\
.58677 \\
.67931 \\
.78382 \\
.90482 \\
1.0477 \\
1.2185 \\
1.4235 \\
1.6690 \\
1.9598 \\
2.2972 \\
2.6798 \\
3.1077 \\
3.5903 \\
4.6011 \\
5.8145 \\
6.9967 \\
8.8049 \\
10.898 \\
12.812 \\
15.351 \\
17.870 \\
21.772 \\
27.075 \\
32.116 \\
36.702 \\
44.635 \\
57.196\end{array}$ \\
\hline
\end{tabular}


TABLE 1. - INPUTS REQUIRED FOR THE DISJOINT PROCEOURE

\begin{tabular}{|c|c|c|}
\hline Program & Inputs & From \\
\hline ODE & $\begin{array}{l}\text { Chamber pressure } \\
\text { Mixture ratio } \\
\text { Area ratio } \\
\text { Fue } 1 \text { and oxydizer enthalptes }\end{array}$ & Specified \\
\hline OOK & $\begin{array}{l}\text { Mole fractions at throat } \\
\text { Throat temperature } \\
\text { Throat velocity } \\
\text { Pressure at throat } \\
\text { Contour points } \\
\text { Throat area } \\
\text { Chamber pressure }\end{array}$ & $\left.\right|_{\text {Specified }} ^{O D E}$ \\
\hline BL IMP & $\begin{array}{l}\text { Wa } 11 \text { temperature profile } \\
\text { wail pressure proffle } \\
\text { Wall contour points } \\
\text { Throat radius } \\
\text { Chamber pressure } \\
\text { Options used in BLIMP program: } \\
\text { Nodal refit on. } \\
\text { Cebeci-Smith turbulence model. } \\
\text { Buddenberg-Wilke mixture formula } \\
\text { for viscosity. } \\
\text { Mason-Saxena with Eucken correction } \\
\text { for thermal conductivity. }\end{array}$ & $\begin{array}{c}\downarrow \\
\text { ook } \\
\text { Specified } \\
\text { Specified } \\
\text { Specified }\end{array}$ \\
\hline
\end{tabular}

Table 2. - INPUTS REQUIRED FOR THE INTEGRATED PROCEDURE

\begin{tabular}{|l|l|c|}
\hline Program & \multicolumn{1}{|c|}{ Inputs } & From \\
\hline TOK.83 & $\begin{array}{l}\text { Contraction ratio } \\
\text { Radius of throat } \\
\text { Upstream throat radius of curvature } \\
\text { Downstream throat radius of curvature } \\
\text { Wall angle of convergent section } \\
\text { Radius of curvature into convergent section } \\
\text { Nozzle exit angle } \\
\text { End-of-circle angle } \\
\text { Wall contour points } \\
\text { Area ratio } \\
\text { Chamber pressure } \\
\text { Mixture ratio }\end{array}$ & \begin{tabular}{|} 
Specified \\
\hline
\end{tabular} \\
\hline
\end{tabular}


TABLE 3. - LIST OF CHEMICAL

REACTIONS AND THREE-BODY

RECOMBINATION-DISSOCIATION

REACTIONS

(a) Chemical reactions

\begin{tabular}{|c|c|c|c|c|c|}
\hline$H$ & + & $\mathrm{O}_{2}$ & $=$ & $\mathrm{OH}$ & +0 \\
\hline 0 & + & $\mathrm{H}_{2}$ & $=$ & $\mathrm{OH}$ & $+\mathrm{H}$ \\
\hline $\mathrm{H}_{2}$ & + & $\mathrm{OH}$ & $=$ & $\mathrm{H}_{2} \mathrm{O}$ & $+H$ \\
\hline $\mathrm{OH}$ & + & $\mathrm{OH}$ & $=$ & 0 & $+\mathrm{H}_{2} \mathrm{O}$ \\
\hline H & + & $0_{2}$ & $=$ & $\mathrm{HO}_{2}$ & $+M$ \\
\hline 0 & + & 0 & $=$ & $\mathrm{O}_{2}$ & + \\
\hline H & + & $H$ & $=$ & $\mathrm{H}_{2}$ & + \\
\hline$H$ & + & $\mathrm{OH}$ & $=$ & $\mathrm{H}_{2} \mathrm{O}$ & +1 \\
\hline $\mathrm{H}_{2}$ & + & $\mathrm{HO}_{2}$ & $=$ & $\mathrm{H}_{2} \mathrm{O}$ & $+\mathrm{OH}$ \\
\hline M & + & $\mathrm{H}_{2} \mathrm{O}_{2}$ & $=$ & $20 \mathrm{H}$ & \\
\hline $\mathrm{H}_{2}$ & + & $\mathrm{O}_{2}$ & $=$ & $20 \mathrm{H}$ & \\
\hline $\mathrm{H}$ & + & $\mathrm{HO}_{2}$ & $=$ & $\mathrm{OH}$ & $+\mathrm{OH}$ \\
\hline 0 & + & $\mathrm{HO}_{2}$ & $=$ & $\mathrm{OH}$ & $+\mathrm{O}_{2}$ \\
\hline $\mathrm{OH}$ & + & $\begin{array}{l}\mathrm{HO}_{2} \\
2 \mathrm{H}_{2} \mathrm{O}\end{array}$ & $\begin{array}{l}= \\
=\end{array}$ & $\begin{array}{l}\mathrm{H}_{2} \mathrm{O} \\
\mathrm{H}_{2} \mathrm{O}_{2}\end{array}$ & $\begin{array}{l}+\quad \mathrm{O}_{2} \\
+\quad \mathrm{O}_{2}\end{array}$ \\
\hline $\mathrm{OH}$ & + & $\mathrm{H}_{2} \overline{\mathrm{O}}_{2}$ & $=$ & $\mathrm{H}_{2} \mathrm{O}$ & $+\mathrm{HO}_{2}$ \\
\hline 0 & + & $\mathrm{H}_{2} \mathrm{O}_{2}$ & $=$ & $\mathrm{OH}$ & $+\mathrm{HO}_{2}$ \\
\hline H & + & $\mathrm{H}_{2} \mathrm{O}_{2}$ & $=$ & $\mathrm{H}_{2} \mathrm{O}$ & $+\mathrm{OH}$ \\
\hline
\end{tabular}

(b) Three-body recombinationdissociation reactions

$\begin{array}{ll}\mathrm{H}+\mathrm{O}_{2} & =\mathrm{H}_{2} \mathrm{O}+\mathrm{M} \\ \mathrm{H}+\mathrm{H} & =\mathrm{H}_{2}+\mathrm{M} \\ \mathrm{M}+\mathrm{H}_{2} \mathrm{O}_{2} & =2 \mathrm{H} \\ \mathrm{H}+\mathrm{OH} & =\mathrm{H}_{2} \mathrm{O}+\mathrm{M}\end{array}$

TABLE 4. - NOZZLE EXIT PLANE RADII AND LENGTHS

\begin{tabular}{|c|r|r|r|r|}
\hline Area ratio & $60: 1$ & $200: 1$ & $400: 1$ & $1000: i$ \\
\hline Radius (in.) & 3.87 & 7.07 & 10.00 & 15.81 \\
Length (in.) & 12.64 & 24.58 & 35.51 & 57.20 \\
\hline
\end{tabular}

TABLE 5. - LIST OF ROCKET ENGINE GEOMETRY PARAMETERS

\begin{tabular}{|c|c|c|c|c|c|c|c|c|}
\hline \multirow[t]{4}{*}{$\begin{array}{l}\text { ECRAT } \\
\text { RWTU } \\
\text { RWTD } \\
\text { RI } \\
\text { EPS } \\
\text { THETA } \\
\text { THETAI } \\
\text { THE }\end{array}$} & $\begin{array}{l}= \\
= \\
= \\
=\end{array}$ & \multicolumn{6}{|c|}{$\begin{array}{l}\text { Contraction ratio of combustion chamber } \\
\text { Upstream throat radius of curvature } \\
\text { Downstream throat radius of curvature } \\
\text { Normalized inlet wall radius } \\
\text { Nozzle expansion ratio (see table for values) } \\
\text { Nozzle attachment angle (see table for values) } \\
\text { Nozzle inlet angle (see table for values) } \\
\text { Nozzle exit angle (see table for values) }\end{array}$} & $\begin{array}{l}=4.223 \\
=2.0 \\
=0.4 \\
=1 \mathrm{E}-4\end{array}$ \\
\hline & \multicolumn{7}{|c|}{ Area ratio } & \\
\hline & & Ang le & $60: 1$ & $200: 1$ & $400: 1$ & $1000: 1$ & & \\
\hline & & $\begin{array}{l}\text { THE TAI } \\
\text { THE } \\
\text { THE TA }\end{array}$ & $\begin{array}{r}25.00 \\
5.05 \\
27.73\end{array}$ & $\begin{array}{r}25.00 \\
5.26 \\
32.61\end{array}$ & $\begin{array}{r}25.00 \\
5.47 \\
35.38\end{array}$ & $\begin{array}{r}25.00 \\
5.74 \\
39.47\end{array}$ & & \\
\hline
\end{tabular}


TABLE 6. - NUMBER OF POINTS

GIVEN TO SPECIFY CONTOURS

\begin{tabular}{|c|c|c|c|c|}
\hline $\begin{array}{c}\text { Procedure } \\
\text { BLIMP }\end{array}$ & $60: 1$ & $200: 1$ & $400: 1$ & $1000: 1$ \\
TDK & 48 & 40 & 40 & 40 \\
8 & 8 & 8 & 11 \\
\hline Initial line points/number of segments \\
\hline TDK & $100 / 3$ & $100 / 5$ & $200 / 5$ & $200 / 5$ \\
\hline
\end{tabular}

table 7. - exit plane values of boundary layer parameters

[Entries are disjoint/integrated procedure values. Numbers in parentheses are $\left(+500^{\circ} \mathrm{R} /-500^{\circ} \mathrm{R}\right)$ wall temperature profile values using integrated procedure.]

\begin{tabular}{|c|c|c|c|c|}
\hline \multicolumn{5}{|c|}{ Area ratios } \\
\hline Parameter & $60: 1$ & $200: 1$ & $400: 1$ & $1000: 1$ \\
\hline $\begin{array}{l}\text { Displacement } \\
\text { thickness (ft) }\end{array}$ & $0.00448 / 0.00455$ & $\begin{array}{l}0.01755 / 0.01587 \\
(.01822 / .01348)\end{array}$ & $0.03560 / 0.02551$ & $0.08701 / 0.06409$ \\
\hline $\begin{array}{l}\text { Momentum } \\
\text { thickness }(\mathrm{ft})\end{array}$ & $.00430 / .00385$ & $\begin{array}{c}.00851 / .00764 \\
(.00737 / .00774)\end{array}$ & $.00851 / .01054$ & $.02045 / .01760$ \\
\hline $\begin{array}{l}\text { Thrust } \\
\quad \text { decrement ( } 1 b f)\end{array}$ & $36.76 / 42.03$ & $\begin{array}{c}41.21 / 51.74 \\
(49.38 / 53.04)\end{array}$ & $43.29 / 55.74$ & $45.43 / 66.96$ \\
\hline $\begin{array}{l}\text { Skin friction } \\
\text { coefficient }\end{array}$ & $.00316 / .00338$ & $\begin{array}{l}.00294 / .00304 \\
(.00303 / .00304)\end{array}$ & $.00279 / .00371$ & $.00270 / .00274$ \\
\hline $\begin{array}{l}\text { Heat loss rate } \\
\text { (BTU/sec) }\end{array}$ & $592.6 / 696.0$ & $\begin{array}{c}631.4 / 789.0 \\
(727.7 / 837.0)\end{array}$ & $655.1 / 847.5$ & $678.7 / 927.4$ \\
\hline
\end{tabular}


TABLE 8. - PERFORMANCE COMPARISON

[Constants: $g=32.1739 \mathrm{ft} / \mathrm{sec} / \mathrm{sec}$;

$p c=1000$ psia; $\left.A_{t}=0.00545415 \mathrm{ft}^{2}.\right]$

(a) The disjoint procedure

\begin{tabular}{|r|c|c|c|c|}
\hline $\begin{array}{r}\text { Area } \\
\text { ratio }\end{array}$ & $\begin{array}{l}C^{\star}(\mathrm{ODE}) \\
\mathrm{ft} / \mathrm{sec}\end{array}$ & $\begin{array}{c}\mathrm{C}^{\star}(\mathrm{BL}) \\
\mathrm{ft} / \mathrm{sec}\end{array}$ & $C_{F}(\mathrm{ODE})$ & $\mathrm{C}_{\mathrm{F}}(\mathrm{BL})$ \\
\hline $60: 1$ & 7575 & 7576.41 & 1.877 & 1.7852 \\
$200: 1$ & $\mid$ & $\mid$ & 1.977 & 1.8577 \\
$400: 1$ & $\downarrow$ & & 2.020 & 1.8934 \\
$1000: 1$ & $\downarrow$ & & 2.063 & 1.9221 \\
\hline
\end{tabular}

(b) The integrated procedure

\begin{tabular}{|r|c|c|c|c|c|c|}
\hline $\begin{array}{r}\text { Area } \\
\text { ratio }\end{array}$ & $\begin{array}{l}C^{\star}(O D E) \\
f t / s e c\end{array}$ & $\begin{array}{l}C^{\star}(B L) \\
f t / s e c\end{array}$ & $C_{F}(0 D E)$ & $C_{F}(B L)$ & \multicolumn{2}{|c|}{$C_{F}(B L)$} \\
\cline { 5 - 7 } & & & & & $+500^{\circ} R$ & $-500^{\circ} R$ \\
\hline $60: 1$ & 7590 & 7622.57 & 1.878 & 1.8723 & & \\
$200: 1$ & $\downarrow$ & & 1.978 & 1.9313 & 1.9299 & 1.9346 \\
$400: 1$ & $\downarrow$ & & 2.021 & 1.9561 & & \\
$1000: 1$ & $\downarrow$ & & 2.065 & 1.9694 & & \\
\hline
\end{tabular}

(c) The disjoint procedure

\begin{tabular}{|r|c|c|c|c|}
\hline $\begin{array}{r}\text { Area } \\
\text { ratio }\end{array}$ & $\begin{array}{c}I_{\text {Sp }}(0 D E), \\
\text { sec }\end{array}$ & $\begin{array}{c}d T, \\
l b f\end{array}$ & $\begin{array}{l}d I_{\text {Sp }} \\
\text { sec }\end{array}$ & $\begin{array}{c}I_{S p}(B L) \\
\text { sec }\end{array}$ \\
\hline $60: 1$ & 459.8 & 36.76 & 11.02 & 444.4 \\
$200: 1$ & 477.7 & 41.21 & 12.35 & 459.9 \\
$400: 1$ & 485.3 & 43.29 & 12.98 & 466.4 \\
$1000: 1$ & 492.9 & 45.43 & 13.62 & 472.7 \\
\hline
\end{tabular}

(d) The integrated procedure

\begin{tabular}{|c|c|c|c|c|c|c|}
\hline \multirow{2}{*}{$\begin{array}{l}\text { Area } \\
\text { ratio }\end{array}$} & \multirow{2}{*}{$\begin{array}{c}I_{S p}(O D E) \\
(S e c)\end{array}$} & \multirow{2}{*}{$\begin{array}{l}d T \\
(1 b f)\end{array}$} & \multirow{2}{*}{$\begin{array}{l}d I_{s p} \\
(s e c)\end{array}$} & \multirow{2}{*}{$\begin{array}{c}\mathrm{I}_{\mathrm{sp}}(\mathrm{BL}) \\
(\mathrm{sec})\end{array}$} & \multicolumn{2}{|c|}{$I_{s p}(B L)$} \\
\hline & & & & & $+500^{\circ} R$ & $-500^{\circ} R$ \\
\hline $\begin{array}{r}60: 1 \\
200: 1 \\
400: 1 \\
1000: 1\end{array}$ & $\begin{array}{l}461.0 \\
479.0 \\
486.5 \\
494.2\end{array}$ & $\begin{array}{l}42.026 \\
51.735 \\
55.745 \\
66.959\end{array}$ & $\begin{array}{l}12.68 \\
15.60 \\
16.82 \\
20.20\end{array}$ & $\begin{array}{l}443.95 \\
457.55 \\
463.44 \\
466.60\end{array}$ & 457.06 & 458.16 \\
\hline
\end{tabular}




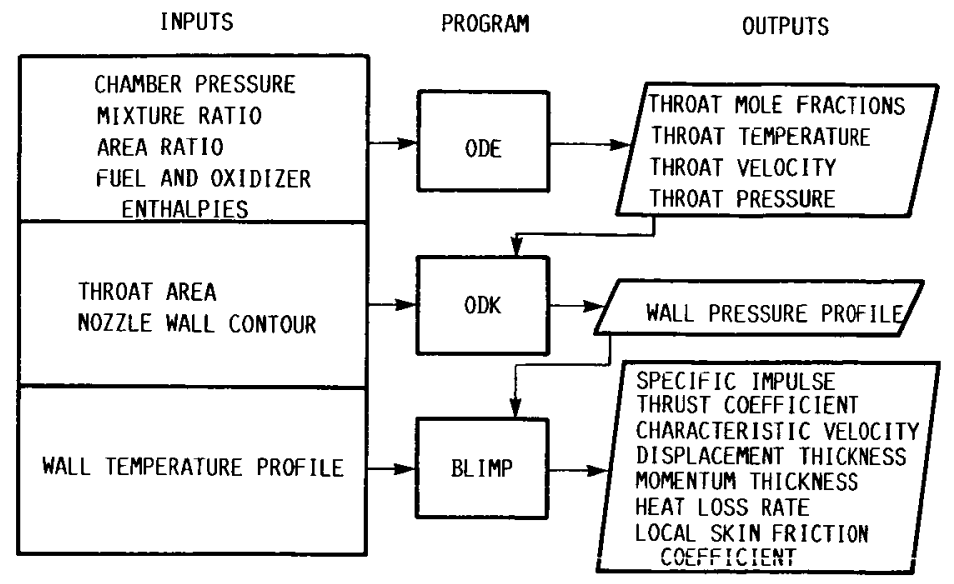

FIGURE 1. - DISJOINT PROCEDURE FLOW DIAGRAM.

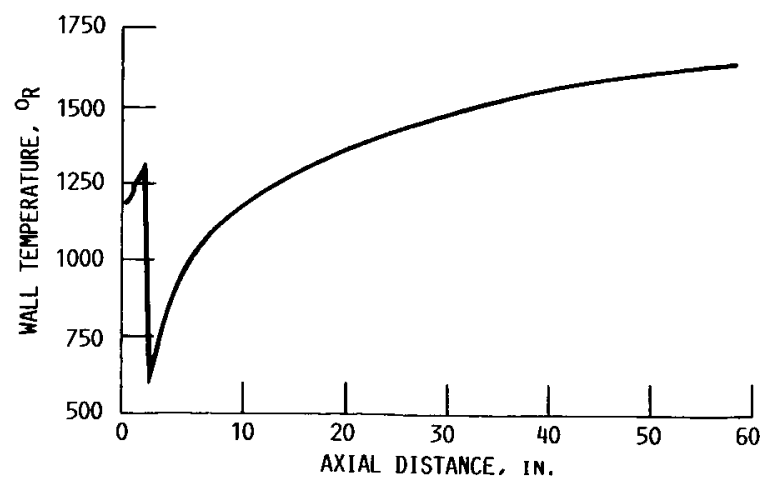

FIGURE 3. - BASELINE WALL TEMPERATURE PROFILE FOR 1000:1 AREA RATIO NOZZLE.

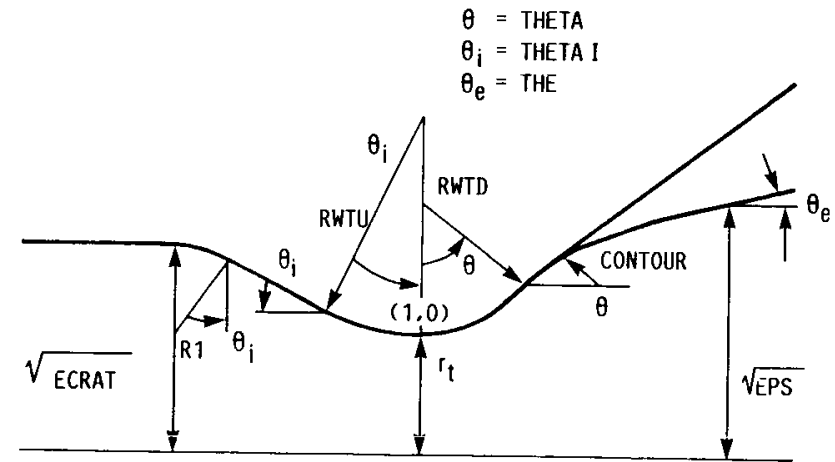

FIGURE 2. - VARIABLES WHICH DESCRIBE NOZZLE GEOMETRY.

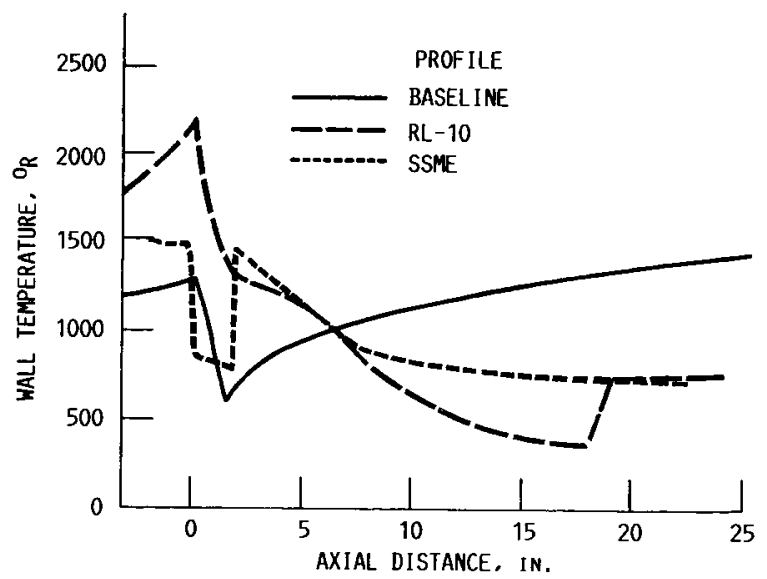

FIGURE 4. - COMPARISON OF BASELINE, RL 10, AND SSME WALL TEMPERATURE PROFILES FOR THE 200:1 NOZZLE. 


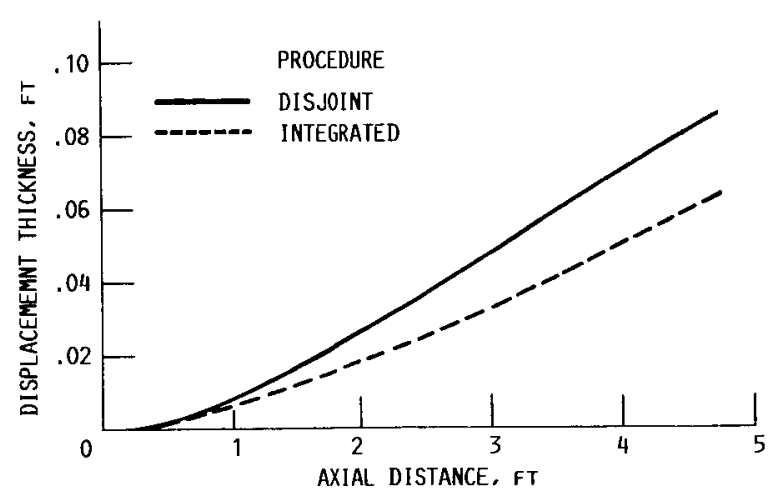

FIGURE 5. - COMPARISON OF BOUNDARY LAYER DISPLACEMENT THICKNESS, NOZZLE AREA RATIO $=1000: 1$.

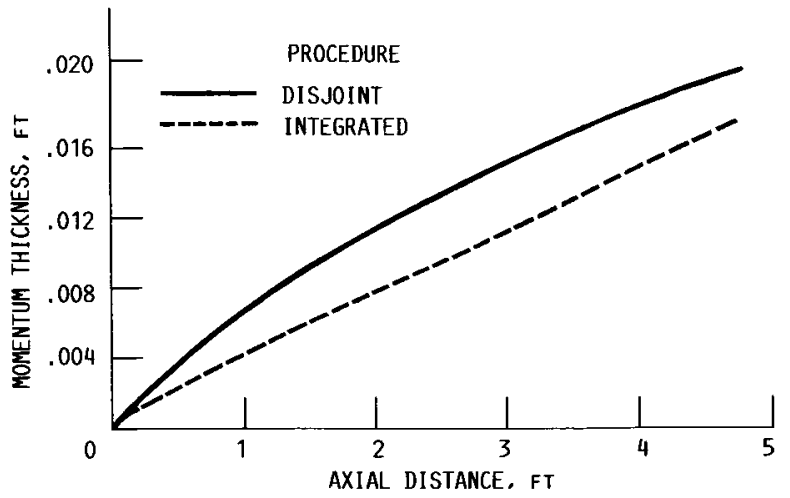

FIGURE 6. - COMPARISON OF BOUNDARY LAYER MOMENTUM THICKNESS. NOZZLE AREA RATIO $=1000: 1$.

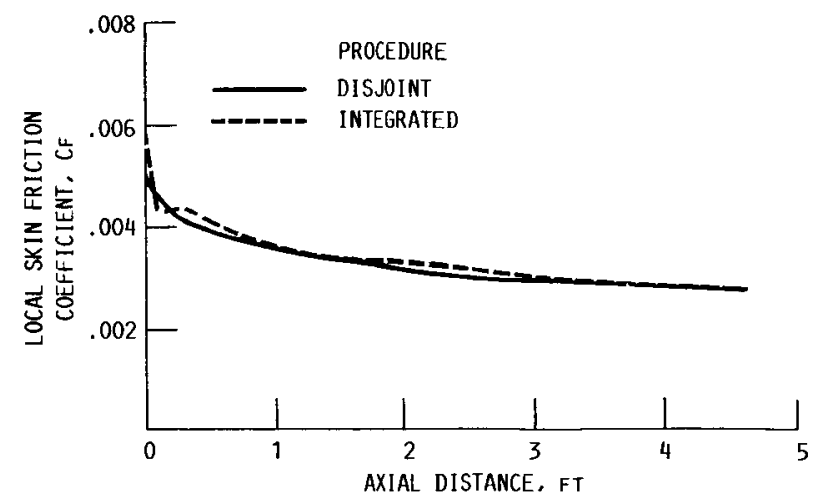

FIGURE 7. - COMPARISON OF LOCAL SKIN FRICTION COEFFICIENT NOZZLE AREA RATIO $=1000: 1$.

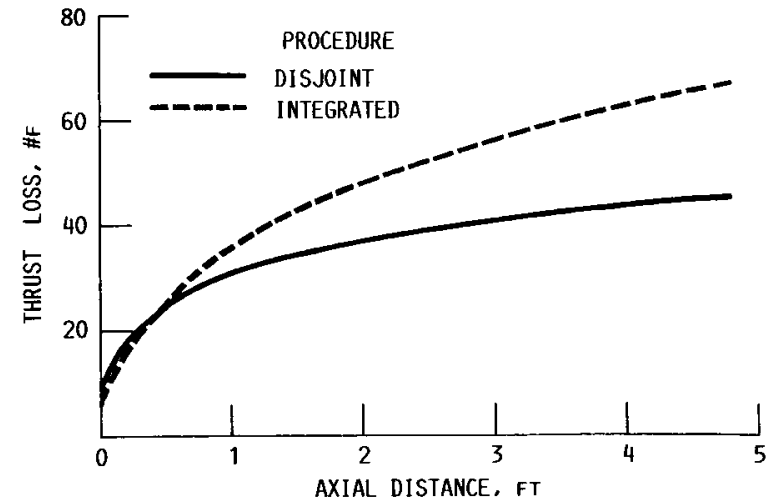

FIGURE 8. - COMPARISON OF THRUST DECREMENT DUE TO BOLNDARY LAYER GROWTH, NOZZLE AREA RATIO $=1000: 1$. 


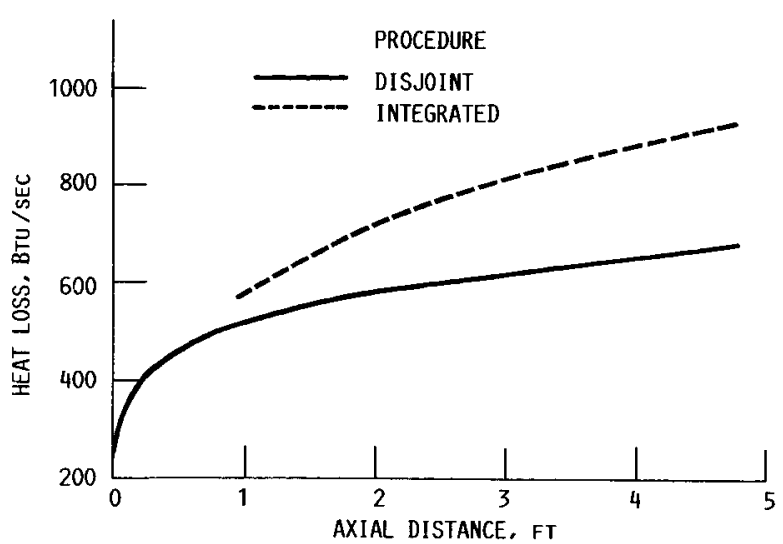

FIGURE 9. - COMPARISON OF HEAT LOSS TO THE WALL, NOZZLE AREA RATI0 $=1000: 1$

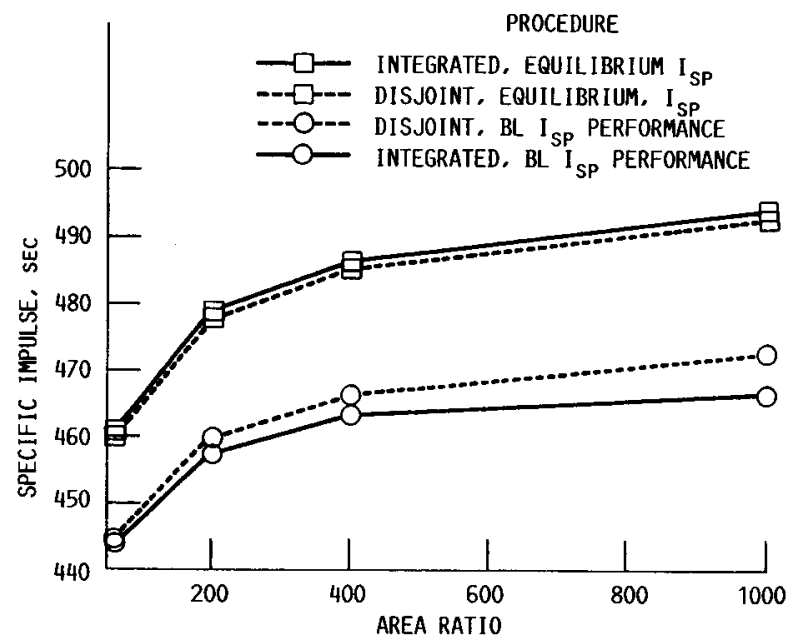

FIGURE 10. - COMPARISON OF INTEGRATED AND DISJOINT PROCEDURES I SP $_{\text {PREDICTIONS. }}$

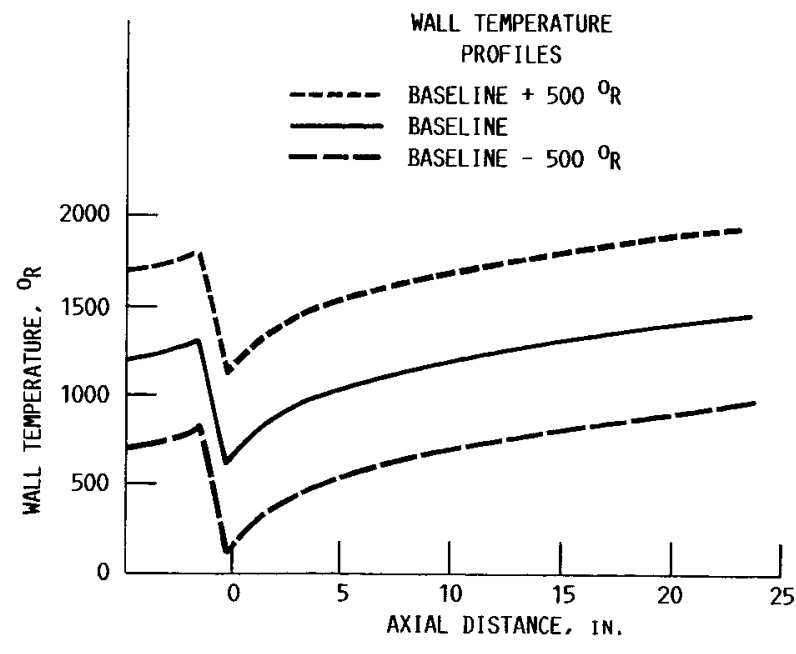

FIGURE 11. - COMPARISON OF BASELINE WALL TEMPERATURE PROFILE, BASELINE + $500^{\circ} R$, AND BASEL INE $-500^{\circ} R$. 


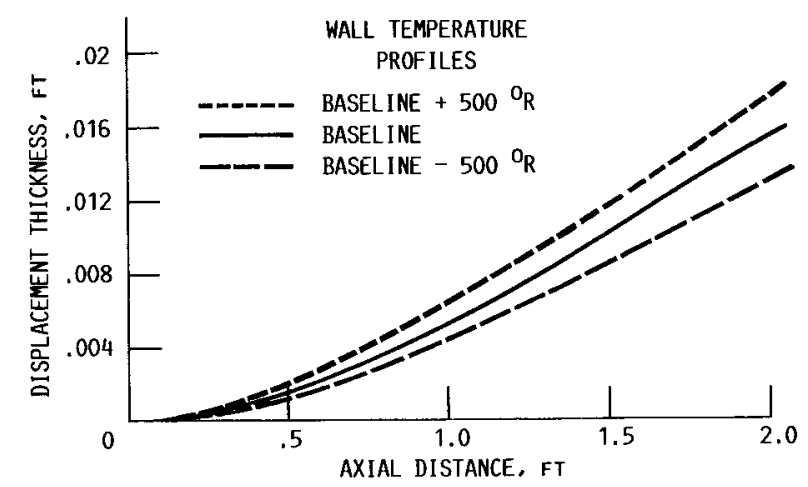

FIGURE 12. - COMPARISON OF BOUNDARY LAYER DISPLACEMENT THICKNESS BETWEEN BASELINE, + $500^{\circ}{ }^{\circ}$, AND - $5000^{\circ} \mathrm{R}$ WALL TEMPERATURE PROFILES.

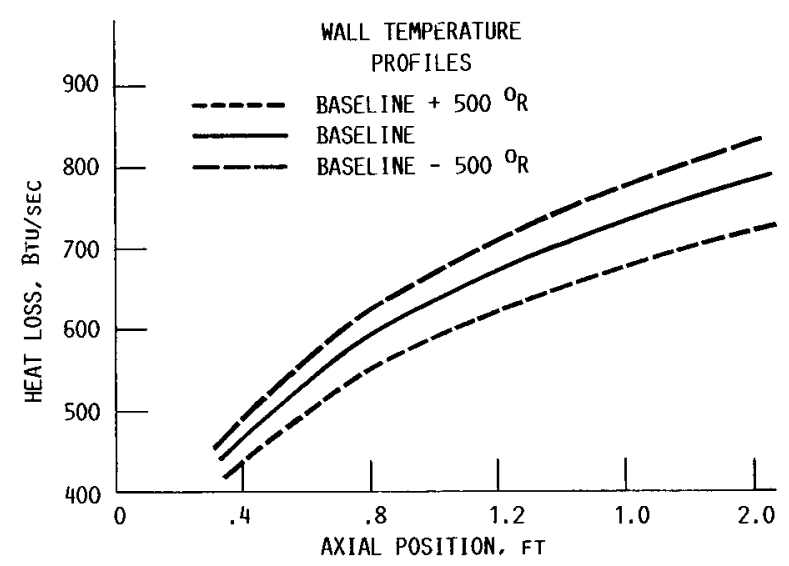

FIGURE 13. - COMPARISON OF HEAT LOSS RATE TO THE WALL BETWEEN BASELINE, $+500^{\circ} \mathrm{R}$, AND $-500^{\circ} \mathrm{R}$ WALL TEMPERATURE PROFILES. 




"For sale by the National Technica! Information Service, Springfield, Virginia 22161 